\title{
Investigación \\ Postmodernidades, campos culturales emergentes y patrimonio
}

Sergio De Zubiría Samper

Dpto. de Filosofia. Universidad de los Andes. Bogotá, Colombia

\section{Resumen}

Tras dos décadas de nutrido debate sobre la cuestión postmoderna, sobre la pertinencia o no del uso del término e incluso sobre la realidad del concepto, los interrogantes planteados y la misma caricaturización irónica con la que algunos han abordado el tema, además de la fuerza de las consideraciones críticas planteadas durante este largo recorrido, pueden considerarse de alguna manera como prueba de su presencia y existencia.

A través de un amplio y pertinente marco teórico, el articulo aborda las formas que el discurso postmoderno ha tomado en los ámbitos prácticos de la cultura, la complejización entre postmodernidades y culturas, las peculiaridades de América Latina y el Caribe frente a Europa, las consecuencias que el debate ha tenido en algunas artes emergiendo nuevos campos culturales $y$, finalmente, las transformaciones notorias, exteriorizadas en complejos movimientos de reconceptualización y resemantización, que ha propiciado esta discusión en la concepción del patrimonio cultural.

\section{Palabras clave}

América Latina

Caribe

Cultura posmoderna

Patrimonio cultural

Política cultural

Posmodernidad

Sociedad contemporánea
Con la distancia que permiten dos décadas de apasionada discusión sobre el término, fenómeno o condición postmoderna, es posible evitar las caricaturas y comprender las consecuencias históricas y paradojales de este discurso. Aunque el vocablo "movimiento postmoderno" fue utilizado por numerosos ensayistas en las décadas de los cincuenta y sesenta del siglo XX, es plausible sostener que su concepto reflexivo sólo se cristaliza a mediados de los setenta. En el ámbito filosófico, ese informe sobre el saber publicado en 1979 con el título La Condición Postmoderna por J. F. Lyotard, va a tener una influencia inmensa sobre los teóricos de la postmodernidad. Para este pensador fundacional del debate, la "condición postmoderna" se manifiesta en la multiplicación de centros de poder, en la disolución de cualquier narración totalizadora que pretenda legitimar el complejo terreno de la actividad y representación social, y en el declive de la autoridad cultural de occidente.

En el ámbito cultural, los inicios del debate estuvieron limitados a algunos interrogantes básicos. El primero, si el término "postmodernidad" ofrece o no una representación "adecuada" de los objetivos y prácticas de la cultura contemporánea, que en enunciados más directos era la duda sobre la existencia de una supuesta "cultura postmoderna". El segundo, la inconformidad con una propuesta que limita o abandona injustamente el vigoroso proyecto cultural aún inacabado de la modernidad, la protesta frente a la pretensión de enterrar la cultura moderna. El tercero, el cuestionamiento de la existencia de algo original o valioso en la pretendida concepción postmoderna de la cultura, la afirmación de cómo la postmodernidad no puede representar un avance o "progreso" en relación con las potencialidades de la cultura moderna:

"Se puede abordar el tema con cinismo, contemplar el conjunto de la moda postmoderna como la Sherezade agasajada por académicos interesados tanto en perpetuarse como en apartar la atención de su creciente irrelevancia. Charles Newman lo designa con otra metáfora si acaso lisonjera. En su opinión, la postmodernidad sólo es el sistema representativo de una inflación del discurso de los estratos sociales, sobre todo en el ámbito de la cultura y la comunicación. Para Newman, el lenguaje crítico y literario ha abandonado deliberadamente cualquier relación con un valor fidedigno, acumulando oscuridad sobre oscuridad en espirales infinitas de autovaloración"(Connor, 1996:13).

Actualmente parece inocuo sostener tesis sobre la negación de la existencia de la postmodernidad o perseverar sobre su caricaturización irónica, porque la fuerza del debate crítico contra ella puede considerarse de alguna manera como prueba de su presencia y existencia. En este sentido los interrogantes iniciales en la dimensión cultural han sufrido importantes desplazamientos y han ganado en densidad

El presente escrito intenta mostrar los actuales procesos de complejización en las relaciones entre postmodernidades y culturas. La 
utilización de esos vocablos en plural, además de ser hoy una necesidad, contiene la conciencia de unas relaciones complejas pero necesarias. Para abordar esta tarea la dividiremos en cuatro momentos. En el primero, los actuales interrogantes y dilemas de los entrecruzamientos entre postmodernidades y culturas. El segundo dedicado a enunciar algunas breves notas sobre el carácter del debate en América Latina y el Caribe. En el tercero, los campos culturales emergentes en los que más consecuencias ha tenido el debate postmoderno. Y en el último, las afecciones y transformaciones notorias que ha traído esta discusión en la concepción del patrimonio cultural.

\section{Interrogantes y contradanzas}

El conjunto de preguntas y problemas que caracterizaron la génesis de esta disputa ha tenido importantes desplazamientos. Quisiéramos aludir tan sólo a algunos de ellos. Antes de preguntarnos si la perspectiva postmoderna refleja fielmente las condiciones reales de la cultura actual, necesitamos considerar las formas que este discurso ha ido tomando en los ámbitos prácticos de la cultura. No preguntamos principalmente por su significado teórico o existencia, sino por su funcionamiento. No es posible separar los temas del debate postmoderno de aquellos contextos socio-culturales en que emerge.

De este desplazamiento en los interrogantes se infieren consecuencias como: existen necesariamente diversas postmodernidades y relaciones distintas con la cultura; la densidad autorreflexiva del debate se ha venido incrementado en los últimos años; su desdoblamiento en un concepto de cultura de época y un estilo artístico; la eliminación de la jerarquía entre artes mayores y menores; la cultura postmoderna no puede ser lo que la teoría postmoderna prescribe que tiene que ser; la critica y la cultura se han interrelacionado fuertemente; el discurso autovalorativo de la postmodernidad ha perdido cualquier indicio de soberbia; representa un reacomodamiento de las relaciones de poder en las instituciones culturales y académicas:

"Ante palabra tan talismánica, tantas veces pronunciada sin saber muy bien si será sólo un significante sin ningún significado detrás, caben varias opciones: hay quien piensa que, en rigor, sólo puede aplicarse a las manifestaciones arquitectónicas que han surgido tras el agotamiento del Estilo Internacional; para otros no es más que un invento de unos cuantos avispados artistas marginales y otros más avispados marchantes; algunos lo han tomado y defendido como una forma de vivir en la que la misma vida, desde las funciones orgánicas a las manifestaciones más sublimes de la creación humana, es la cultura; también hay quienes piensan que la postmodernidad designa a la cultura de toda una época, la nuestra, independientemente de que haya o no unos estilos arquitectónicos con unas características determinadas e independientemente de que ese arte influya o convenza a unos pocos o a las masas" (De Vicente, 1989:37).
Intentaremos exponer la densidad reflexiva que ha adquirido este debate a partir de una posible cartografía de lo postmoderno inspirados en los trabajos de Carlos Thiebaut, Agnes Heller, Gianni Vattimo y Steven Connor. La procedencia de cada uno de estos cuatro pensadores muestra tanto la diversidad crítica que ha tomado como la riqueza de matices.

El rótulo de lo postmoderno, que para C. Thiebaut posee mucho de confusión, engloba tanto constataciones de agotamiento temporal ("después de la modernidad") como de agotamiento teórico ("más allá del programa de la modernidad"). En medio de su carácter confuso, remite a cuatro problemas/momentos: 1. Las sociedades contemporáneas (postindustriales informatizadas) están desvaneciendo los límites estables de las racionalidades modernas; 2. La profunda pluralización de los lenguajes y los asuntos relativos a su inconmensurabilidad; 3. El desvanecimiento de la centralidad del sujeto y de la supuesta intencionalidad consciente; 4. El colapso de la historia en su visión del progreso.

A. Heller establece una interesante distinción entre un concepto "irreflexivo" de postmodernidad (prolonga las grandes narrativas; todo es relativo; todas las culturas son iguales; etc.) y un concepto "reflexivo" de postmodernidad, que se caracteriza por su profunda concepción autorreflexiva y por ponerse en cuestión a si misma constantemente. El concepto irreflexivo se acompaña siempre de dos sombras: el fundamentalismo y el cinismo. El reflexivo, en cambio, reconoce desde un principio la existencia de diversas versiones de la postmodernidad reflexiva y critica cualquier pretensión neo-fundamentalista. Algunos de los rasgos propuestos por $\mathrm{A}$. Heller, que de alguna manera juntan a las postmodernidades reflexivas, son: 1. La postmodernidad no es un estadio o período que siga a la modernidad, es la expresión de una conciencia auto reflexiva de la modernidad misma; 2. Los postmodernos no reclaman para ellos una posición privilegiada en la historia; 3. La condición postmoderna parte de la conciencia de la contingencia personal como rasgo de la actual situación existencial, en cambio el hombre moderno, según Pascal, se encuentra aprisionado entre el cero y el infinito; 4. El moderno marginaliza el presente a través de la proyección de un futuro infinito y siempre abierto, el postmoderno no, la postmodernidad no es la hipertrofia del exclusivo tiempo futuro.

El pensador italiano G. Vattimo, quien en la década de los ochenta fue el mayor defensor de que el término postmoderno "sí tiene sentido", postula que las claves de lo postmoderno en su sentido filosófico podrian ser: 1. El abandono de cualquier vertiente del "fundamentalismo" metafísico en la búsqueda de un estado de ánimo nihilista y hermenéutico (de la "verdad" como certeza a la "verdad" como interpretación y perspectiva; se vuelve cada vez menos concebible la idea de "una realidad"); 2. En el fin de la "idea unitaria" de historia, no hay una historia única, transitamos de la experiencia de la "utopía" a la posibilidad de las "heterotopías" (el ser moderno ya no es el único destino, ni el único valor determinante); 3. La experiencia de 


\section{Investigación}

Postmodernidades, campos culturales emergentes y patrimonio

\section{Sergio De Zubiría Samper}

lo postmoderno se enlaza con la vivencia de la sociedad de la comunicación generalizada, la sociedad de los medios masivos de comunicación; 4. Se están modificando tanto la concepción como las experiencias posibles del tiempo. La avidez "moderna" de futuro como el único tiempo valioso, es tan solo una de esas posibles experiencias; podemos abrirnos a posibilidades del futuro como pasado o al eterno retorno de lo mismo.

Para el teórico inglés de la literatura Steven Connor, quien ha investigado profundamente las transformaciones postmodernas en el arte y la cultura, la polémica postmoderna encierra de forma compleja y reflexiva indicios de una transformación en el papel tradicional de la crítica. Una de esas señales es el aparente fracaso de la crítica en cuanto a su objetivo y los contornos borrosos entre la función crítica y la creativa. Otro indicio es la desconfianza generalizada ante la capacidad de todo tipo de lenguaje para exponer "verdades" de forma transparente u objetiva, sospecha que se acentúa frente al lenguaje teórico. También destaca la enorme difusión de teorias del "discurso" que pretenden reemplazar las teorías del "lenguaje", es decir, teorias que enfatizan la necesidad de situar toda declaración en sus contextos sociales particulares y no en reglas o sistemas lingüísticos abstractos. La "teoría postmoderna" manifiesta la compleja red de conjunciones entre conocimiento, poder y lenguaje. Constituye un ataque a la política de representación en el discurso cultural.

\section{Resistencias latinoamericanas}

En el contexto de América Latina, desde finales de la década del ochenta del siglo XX, la actitud ante la polémica postmoderna se ha visto enfrentada a resistencias, simplificaciones y muy diversas motivaciones.

De manera provisional y no exhaustiva, consideramos que algunas de las resistencias dominantes han sido las siguientes: a) Es considerada una discusión pertinente a las realidades europea y norteamericana, que en el contexto latinoamericano es simplemente una "moda" o bien resulta ajena a la realidad social y cultural de nuestro continente; b) La imposibilidad de comparar la regularidad del desarrollo europeo con la "heterogeneidad" y fragmentariedad de las temporalidades latinoamericanas impiden la utilización de prefijos unificadores como "pre" o "post"; c) No es posible hablar de postmodernidad porque nuestra modernidad no sólo es desigual sino inacabada o inconclusa. Tendríamos primero que terminar de realizar o "completar" la modernidad en la región para ahí si ingresar a "una etapa" postmoderna; d) Los esquivos rasgos que configuran la noción de postmodernidad la convierten en estéril 0 inocua en nuestras coordenadas vitales; e) La postmodernidad es tan sólo una "seudomodernidad" (J. Corradi) o una modernidad como "simulacro" (A. Avellaneda).
Los malentendidos y simplificaciones provienen principalmente de la aceptación "ingenua" o "no mediada" de una supuesta condición postmoderna sin más en América Latina. Algunas de estas simplificaciones expresan tesis como: a) Las "únicas" culturas y sociedades postmodernas son las latinoamericanas. Existe una especie de "acento latino" de la postmodernidad, sugerido por G. Vattimo en La Sociedad Transparente, pero luego rectificado por él; b) Éramos postmodernos vitalmente sin saberlo y anteriormente al discurso filosófico postmoderno. Y esta condición la ratifica el vigor de nuestro realismo-mágico, exotismo y diversidad; c) Si las demás sociedades están ya ingresando en la "era postmoderna", para qué insistir tanto en la región en la construcción de la modernidad: la tarea del presente es profundizar y consolidar el carácter postmoderno; d) Al ser el arte y la literatura -no la ciencia y la técnica- nuestras formas dominantes de autorreconocimiento, patentizamos nuestra cercanía a una especial condición postmoderna latinoamericana.

La romanista alemana Ingrid Galster, considera que la discusión actual sobre el postmodernismo en la teoria literaria hispanoamericana, gira en torno a tres posiciones básicas: 1 . Un rechazo categórico del paradigma; 2. Una adopción reinterpretada del concepto para Hispanoamérica; 3. Una actitud que reclama el origen del paradigma para América Latina.

La primera posición es representada, ante todo, por George Yúdice quien reitera el conocido argumento de muchos latinoamericanos: si ni siquiera la modernidad ha logrado entrar en el subcontinente, mal puede hablarse de postmodernidad. Esta noción es sólo aplicable a los países desarrollados política y económicamente, por tanto, su aplicación a países en vías de desarrollo conforma una nueva forma de eurocentrismo.

La segunda reacción, que adopta reinterpretando el concepto, tiene su más adecuado exponente en la obra Culturas Hibridas de N. Garcia Canclini, pero a esta posición, según la romanista, también pertenecen el uruguayo Jorge Ruffinelli y el chileno José Joaquín Brunner. Recuperan las nociones de heterogeneidad e hibridismo revaluadas por los postmodernos y señalan rasgos distintos de sus manifestaciones en América Latina. Tienden -según I. Galster-, cargados de un sinnúmero de paradojas, a reivindicar una postmodernidad con rasgos emancipatorios, llegando por momentos a considerar todas las formas de apropiación de la cultura en los sectores populares como "postmodernas".

La tercera actitud sostiene la tesis del origen latinoamericano del postmodernismo literario y considera componente básico su condición ficcional o realismo mágico. Sus representantes trasladan el origen del postmodernismo como "código literario" hacia Latinoamérica y exigen situar la interpretación de los textos hispanoamericanos en un marco libre de eurocentrismo. Para ello es ineludible rechazar el logocentrismo binómico desde una diferencia independiente de las categorías de identidad, negación y oposición. 
1. La "condición postmoderna" se manifiesta en la multiplicación de centros de poder, en la disolución de cualquier narración totalizadora que pretenda legitimar el complejo terreno de la actividad y representación social

2. La postmodernidad sólo es el sistema representativo de una "inflación del discurso" de los estratos sociales, sobre todo en el ámbito de la cultura y la comunicación
3. Lo postmoderno remite, entre otros problemas/momentos, a la profunda pluralización de los lenguajes y los asuntos relativos a su inconmensurabilidad

4. (...) y también remite al desvanecimiento de la centralidad del sujeto y de la supuesta intencionalidad consciente
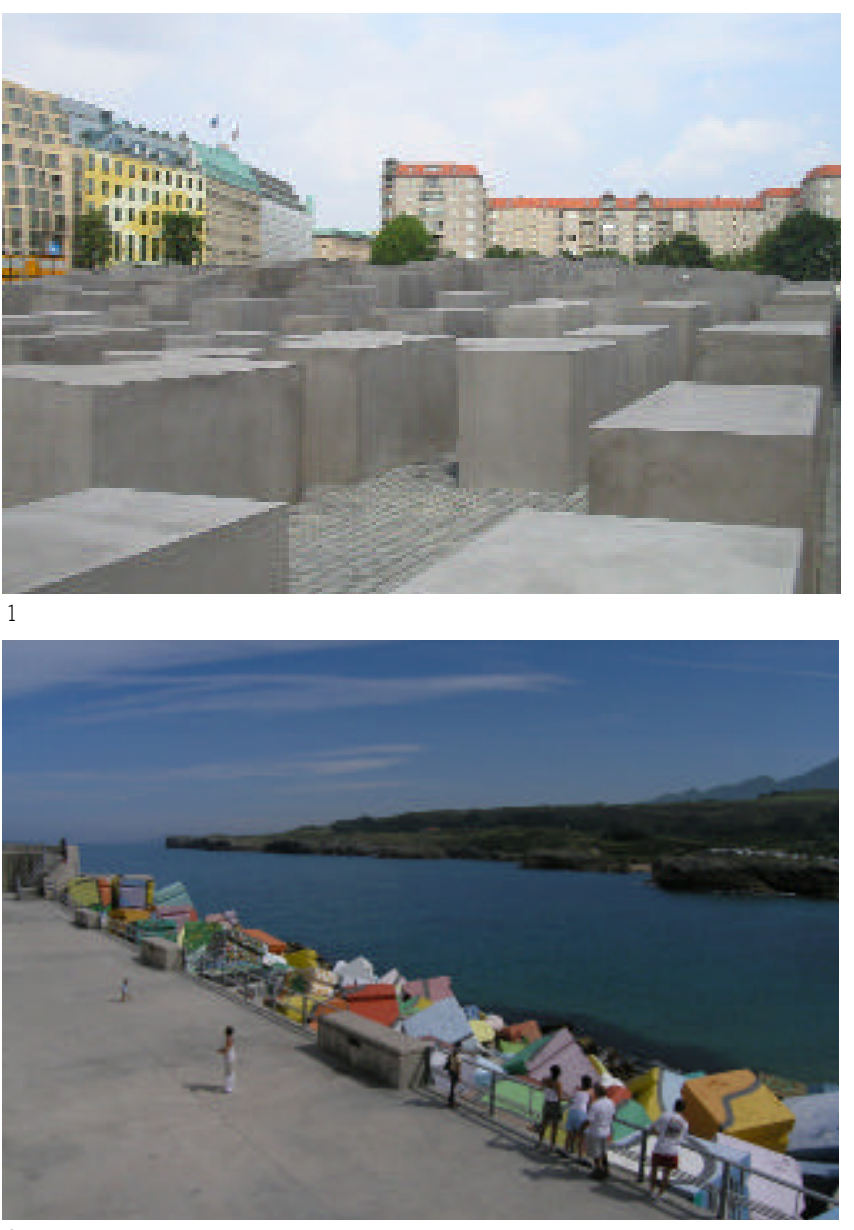

Para nuestra autora el mayor exponente de este "credo postmoderno" es el ensayista colombiano Carlos Rincón, quién realiza una caracterización de la teoría literaria y sus nexos con la discusión postmoderna, pero aún muy limitada al debate literario y sin tener en cuenta una compleja red de posiciones y matices intermedios.

Por ahora aludamos a las que, consideramos, conforman las motivaciones más notorias, que despiertan o expanden la polémica en el continente, la cual sitúa I. Galster "no antes de mediados" de la década de los ochenta.

Las incitaciones son demasiado diversas, pero desde nuestra perspectiva nos parece importante destacar algunas que consideramos, una vez situados a distancia tanto de las resistencias como de las simplificaciones, tendrán agudas consecuencias en el debate: a) Revincular y retomar estrechos vínculos entre la filosofía y la cotidianidad, especialmente en los ámbitos de los discursos sociales, las formas de comunicación y las culturas; b) Repensar e investigar las características de nuestra(s) modernidad(es) y las manifestaciones

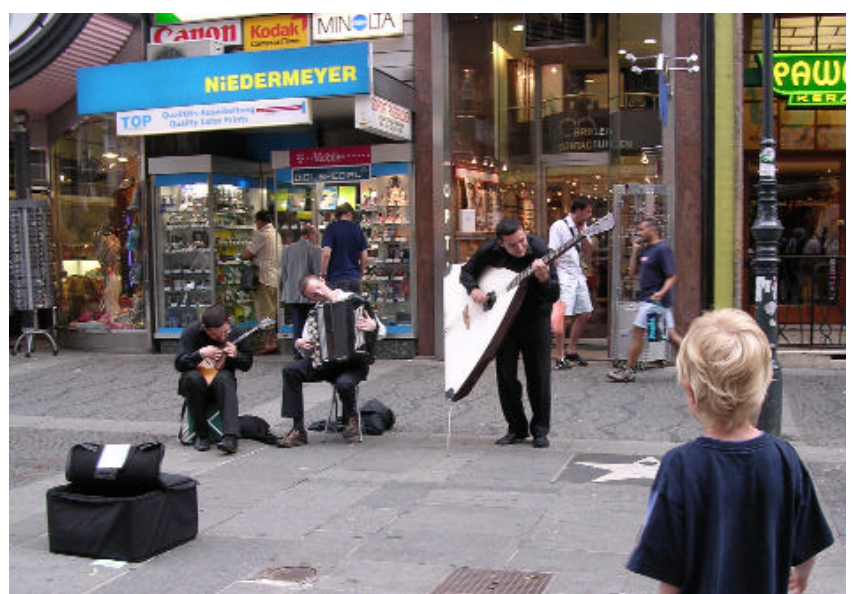

2

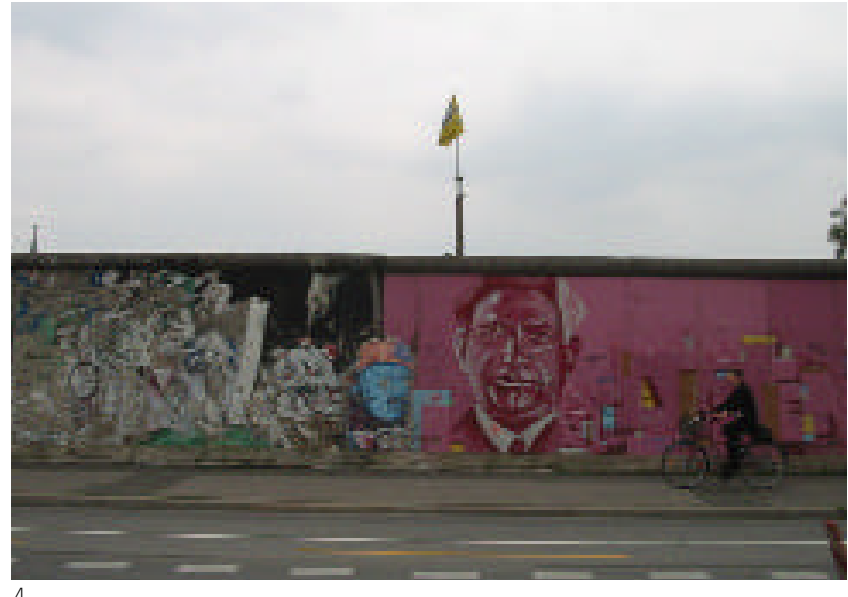

peculiares de la "crisis" y límites de ésta(s) en el continente latinoamericano; c) Discutir los nexos actuales e históricos entre modernidad, modernización, modernismo y tradición en la experiencia histórica de la región; d) Estudiar los efectos sociales, políticos y culturales en América Latina de los procesos contemporáneos de "transnacionalización" y "globalización"; e) Analizar las incidencias del debate modernidad-postmodernidad-tradición en Latinoamérica para los procesos de "homogeneización" y "heterogeneización" social y cultural; f) Explorar las transformaciones éticas y estéticas que las experiencias postmodernas han generado en los mundos de la vida y las reflexiones filosóficas.

Autores como Nestor Garcia Canclini, Fernando Calderón, José Joaquín Brunner, Jesús Martín-Barbero, Norbert Lechner, Adolfo Sánchez Vásquez, Beatriz Sarlo, Nelly Richard, George Yúdice, Bernardo Subercaseaux, Guillermo Hoyos Vásquez y otros, han subrayado la complejidad e importancia del debate postmoderno en Iberoamérica, construyendo hasta la fecha obras teóricas consolidadas y significativas sobre el tema. Hoy ya es posible, más allá de los malentendidos y reti- 


\section{Investigación \\ Postmodernidades, campos culturales emergentes y patrimonio \\ Sergio De Zubiría Samper}

cencias, elaborar una evaluación aproximada sobre estos cerca de diez años de importante disputa postmoderna latinoamericana.

En este amplio conjunto de investigadores podemos aludir a algunas sugerentes conclusiones de J. Martín-Barbero. Para este pensador la postmodernidad latinoamericana ha efectuado importantes desplazamientos en dimensiones como: las experiencias culturales actuales no corresponden excluyentemente a determinadas etnias o clases sociales o grupos sociales únicos; generado hibridaciones entre lo autóctono y lo extranjero, lo popular y lo "culto", lo tradicional y lo moderno; la postmodernidad antes que intentar sustituir la modernidad viene a reordenar las relaciones de la modernidad con las tradiciones; recuerda que la modernidad latinoamericana sólo se puede hacer experiencia colectiva si asume sus componentes constitutivos de la tradición y logra "dislocaciones" sociales y perceptivas de "cuño" postmoderno; recalca el carácter peculiar de nuestra heterogeneidad cultural.

En cuanto a algunos posibles rasgos de nuestra postmodernidad, Martin-Barbero considera que ésta ha reivindicado con vigor la heterogeneidad social y cultural como un valor, pero mientras en los países "centrales" el elogio de la heterogeneidad y la diferencia va acompañado de la disolución de cualquier idea de comunidad, en América Latina la experiencia postmoderna tiende a asociar la heterogeneidad con dinámicas sociales ligadas a alguna noción de comunidad. Nociones de comunidad divergentes, pero en general cercanas a sentidos de reconstrucción y a veces distantes de la idea de una comunidad "rescatada" del pasado. La postmodernidad replantea radicalmente los vínculos con el evolucionismo y el tradicionalismo. Por esto decide acuñar una noción seductora y creativa: "modernidad no-contemporánea". Las tensiones o "divorcio" entre la modernización económica y el modernismo cultural, la construcción contradictoria de lo nacional y el reordenamiento que conlleva la postmodernidad latinoamericana en las relaciones tradición/modernidad, conforman tres ejemplos relevantes de la no-contemporaneidad y carácter contradictorio de nuestra modernidad.

El escenario más cercano a las manifestaciones postmodernas en América Latina, para Martín-Barbero, debe ser la investigación de importantes transformaciones que actualmente experimentamos en los nexos entre comunicación y cultura; dos ejemplos de ellas, son nuestros nexos con la televisión y la telenovela.

\section{Campos culturales emergentes}

Se ha insistido en las consecuencias que el debate postmoderno ha tenido en algunas de las artes, especialmente en la arquitectura, artes visuales, literatura, diseño, televisión, vídeo y cultura popular. Constituye una especie de lugar común que su primera expresión es la alteración de la clasificación de los siete géneros artísticos de la modernidad y, como la arquitectura -no reconocida como arte por esta tipología- se considera a sí misma el "primer" arte postmoderno. Consideramos que además de las notorias incidencias en las artes, son muy importantes para la sociedad y la cultura la emergencia de transformaciones significativas en los siguientes campos: las politicas culturales, multiculturalismo, postcolonialismo, posibilidades éticas, entre otros muchos ámbitos.

Gran parte de la teoría estética postmoderna rechaza la separación moderna entre el ámbito del arte y otras actividades sociales (moral, política, ciencia, etc.); pretende restaurar las dimensiones políticas y de resistencia de toda actividad estética y cultural. Los últimos años han presenciado un gran interés por un conjunto de textos y prácticas culturales que la crítica académica había evitado, invisibilizado u omitido. Críticos culturales contemporáneos como Raymond Williams, Roland Barthes y Stuart Hall, han abordado temas como el deporte, los peinados, la moda, los juegos, los rituales, las trayectorias, etc., pretendiendo otorgarles el mismo grado de sofisticación teórica que cualquier producto artístico y cultural. Aspecto central de sus propósitos es expandir la cultura en todos los espacios sociales y la "estetización" de los ámbitos políticos, económicos y sociales. Perspectiva que otorga a la postmodernidad una doble cara: la rehabilitación de las relaciones entre política y cultura, pero también la tentación de su neutralización. Contiene, de alguna manera, un proyecto dual: rehabilita la función de crítica y de resistencia de la política cultural, pero también, al disolver las fronteras de lo político, vía su expansión y descentralización, puede conllevar a la inocua posición de que nada es real y efectivamente político. Favorece intersecciones político-culturales con raza, género, edades, ecologismo, derechos de los animales, formas culturales del poder, pero deja inermes ante el interrogante de contra quién es necesario y prioritario luchar. El poder y la política se difuminan y deslocalizan; con ello nada es posible porque nada importa a nivel real:

"Las últimas obras de Michel Foucault y otros teóricos del discurso como Michel Pecheux, han señalado el desarrollo de una política cultural postmoderna en dos direcciones. La primera sugiere que la cultura ya no puede ser considerada como un simple ámbito de representaciones, inmóvil, inmaterial y a cierta distancia de los crudos hechos de la vida real, pues la teoría del discurso considera a las formas y ocasiones de representación como el poder en sí (en vez de como mera reflexión sobre las relaciones de poder que aparecen en cualquier parte). La segunda sugiere que el poder se entiende mejor en términos micropolíticos de una red de relaciones de poder que subsiste en cualquier aspecto de la sociedad, más que en términos metafóricos de grandes conjuntos o bloques monolíticos de clases o estados. Este panorama es acorde con un desplazamiento de las narraciones globales que abarcan la historia y la política, y con un énfasis valorativo en formas locales o particulares de diferencia y lucha" (Connor, 1996:147).

La extensión propiciada por el postmodernismo de la noción de cultura y su sensibilidad a los conflictos políticos de "pequeña escala", son importantes aportes del discurso postmoderno, pero 
5. No hay una historia única, transitamos de la experiencia de la "utopia" a la posibilidad de "heterotopías"

6. En las transformaciones postmodernas (...) destaca la difusión de teorias del "discurso" que pretenden reemplazar las teorías del "lenguaje"

las dificultades mayores se hacen patentes en algunos de los términos metafóricos y espaciales de la política cultural postmoderna: espacio y territorio; centro y margen; dentro y fuera; posición y limite. Se trata entonces de políticas culturales de los "márgenes" o "sin límites" o sólo "del afuera". Algunos investigadores han acuñado la categoria de "romance o seducción con lo marginal".

En el ambiente europeo de inicios del siglo XXI estas discusiones inciden bastante en las polémicas feministas, mientras, en América Latina en los rasgos de nuestro abordaje del multiculturalismo y postcolonialismo. Por ejemplo las posiciones de Julia Kristeva y Craig Owens están siempre interrogando por el "lugar" desde el cual las mujeres pueden hablar o representarse y por la articulación del potencial subversivo del discurso marginal para evitar la repetición del gesto patriarcal. La escritura feminista de cuño europeo, en muchos casos, proyecta a lo femenino como el Otro del sistema patriarcal. En términos de Nancy Fraser, el "feminismo de la diferencia", como el feminismo de la "diferencia entre las mujeres", redime la polémica sobre el mapa conceptual de centro y margen.

Las características que definen el multiculturalismo en América Latina y el Caribe cuestionan la pretendida condición de homogeneidad y superioridad de las culturas dominantes, se insiste en la condición multicultural de nuestras sociedades, se interesa en la semantización de las fronteras culturales y en la definición de umbrales a partir de los cuales se construyen las diferencias. Acentúa el análisis de los procesos de estructuración de las identidades colectivas en lo relativo a la conformación de umbrales de adscripción y diferencia. Las concepciones multiculturalistas en la región acentúan la condición cultural de los procesos políticos y la condición sociopolítica de los procesos culturales:

"Las perspectivas multiculturalistas cuestionan la lógica desde la cual se conforman los metarrelatos dominantes tales como el eurocentrismo, el racismo o el sexismo. Desde esta posición, se subraya la condición multicultural de nuestras sociedades y se cuestiona la lógica desde la cual se valida el monoculturalismo dominante... El multiculturalismo busca la deconstrucción de los centros de poder colonial y la destrucción de los discursos racistas y excluyentes, subrayando que los enemigos de la conformación de sociedades más justas y democráticas no son las diferencias culturales, sino las desigualdades sociales" (Valenzuela, 2003:17).

Estas mismas complejidades las encontramos en lo que se ha denominado los estudios poscoloniales y su mapa conceptual centro-periferia. Para estos el colonialismo no termina con la independencia política de los países coloniales, sino pervive en imaginarios y representaciones neocoloniales. Por ejemplo, para J. F. Lyotard, la dominación del centro se manifiesta en la subordinación lingüística de la persona gramatical a la persona integradora pero represiva de un "nosotros universal". Para Edward Said, Oriente no fue el interlocutor de Europa, sino su Otro silencioso. En Tzvetan Todorov, el acontecimiento ejemplar escogido es la historia del descubrimiento de América; y la perspectiva interpretati-
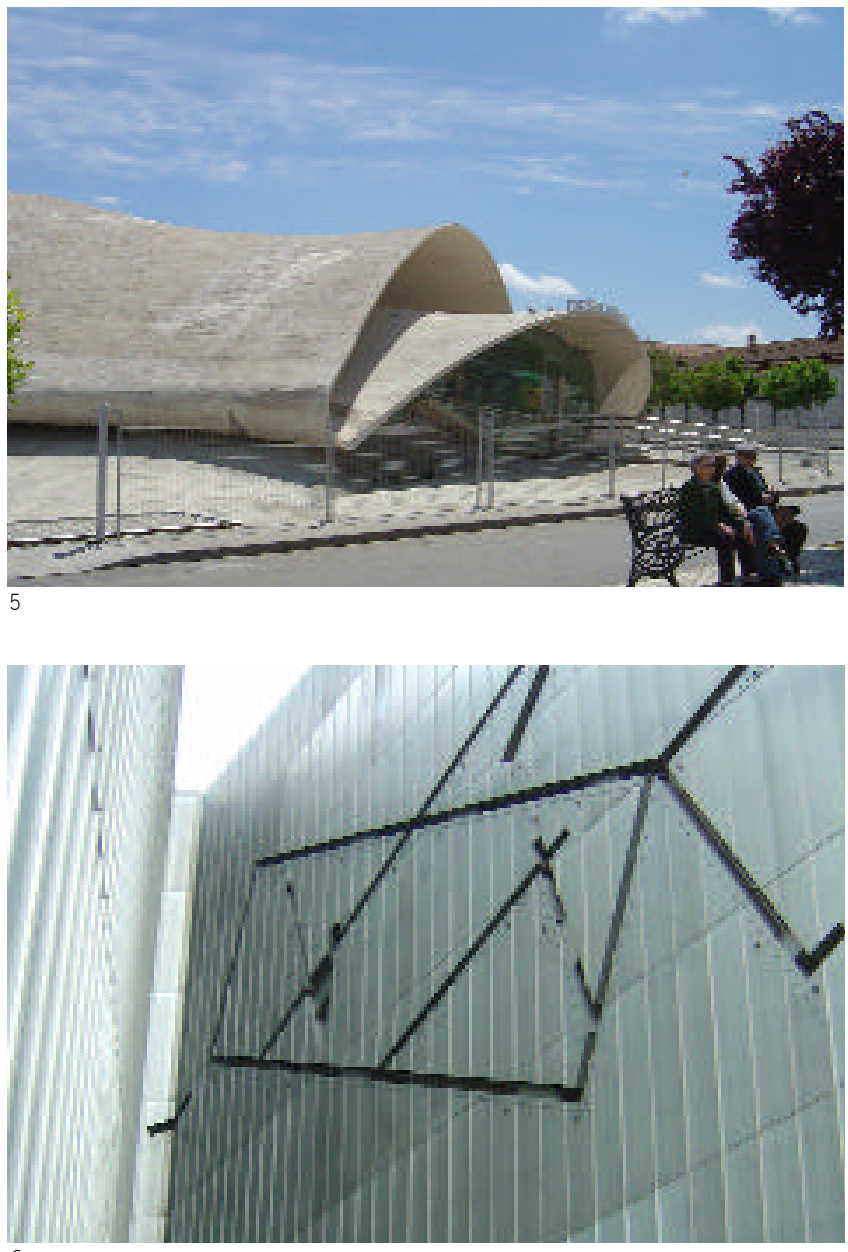

va, las profundas consecuencias que esta relación con el prójimo (todo otro) ha tenido en la historia de Europa y de Occidente.

Toda teoría poscolonial plantea que el énfasis reside en la articulación de los márgenes o lo que se ha proyectado como marginal o periferia. Se trata no sólo de las consideraciones sobre el poder real, sino también sobre los discursos, sistemas de metáforas y regímenes de imágenes que han sido diseñados para silenciar y marginar todo aquello que pueden encarnar en la representación. Tenemos que indagar cómo se nos ve desde los llamados "países desarrollados" y las formas en que nos vemos nosotros mismos y los vemos a ellos. En esa compleja dialéctica entre descubrir, conquistar, amar y conocer, como lo ha postulado Todorov.

La dificultad mayor empieza al reconocer que la articulación de los márgenes puede tomar formas diferentes. La manera directa y binaria sería la simple inversión. Lo que ha sido periferia ahora convertido en centro y el anterior centro transmutado en periferia. Las investigacio- 


\begin{tabular}{|l|}
\hline Investigación \\
Postmodernidades, \\
campos culturales \\
emergentes y patrimonio \\
Sergio De Zubiría Samper
\end{tabular}

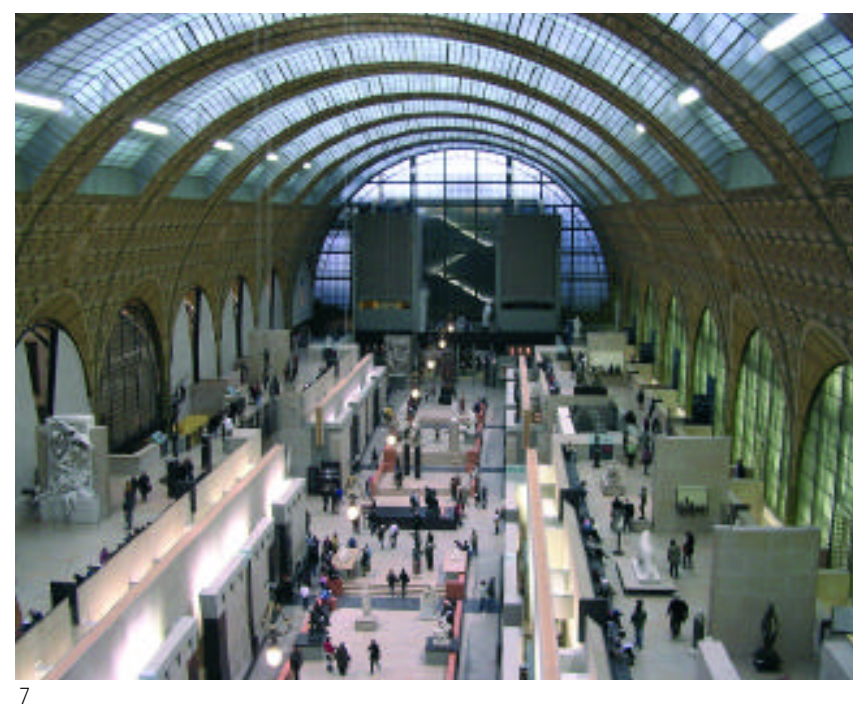

nes culturales recientes desconfian de estos modelos de oposición binaria, al sostener que pueden proceder y reproducir estructuras de pensamiento colonial. La proclamación de la marginalidad como un mecanismo de internalización y aceptación de esa condición:

"En opinión de Nelly Richard, el dominio de la teoría postmoderna supone un cuchillo de doble filo en el caso de la política post-colonial latinoamericana. En primer lugar, la teoría postmoderna legitima la desaparición del centro o de la idea de un centro, dividiéndola en microterritorios disidentes, constelaciones de voces y pluralidades de significados, permitiendo y promoviendo la especificidad y el regionalismo, las minorias sociales y aquellos proyectos políticos de alcance local o los vestigios de la tradición y las formas suprimidas del conocimiento. Pero estas diferencias están hipotecadas en una codificación teórica que siempre reafirmará la primacía de los conocimientos (postmodernos) de Occidente" (Connor, 1996:173).

Más allá de las limitaciones formales del poscolonialismo y de las dificultades en las maneras de articulación del mapa conceptual centroperiferia, en América Latina estas investigaciones giran en torno a tres ejes: su ligazón a una historia intelectual donde cohabitan marxismo, postestructuralismo y postmodernismo; la afirmación que en todas las sociedades poscoloniales prevalecen elementos que las mantienen sujetas a diversas formas de dominación; y la necesidad de construir un diálogo crítico entre las representaciones externas de nuestras realidades y nuestras propias narraciones y representaciones.

\section{Postmodernidades y patrimonios}

Tal vez el primer pensador que avizoró las profundas mutaciones del arte y la cultura en el "corto" siglo XX fue Walter Benjamin y por ello su condición de fundador de la estética contemporánea. Dos de sus
7. Se crea una sensibilidad de masas (...) que aspira a "acercar" espacial y humanamente todas las cosas, como también "adueñarse" ante todo de la imagen, la copia, la reproducción

8. Estamos experimentando diversos y complejos movimientos de reconceptualización y resemantización del patrimonio. El primer desplazamiento es el reconocimiento del patrimonio no sólo incluyendo la herencia pasada, sino también los recientes bienes y expresiones culturales, visibles e invisibles, tangibles e intangibles

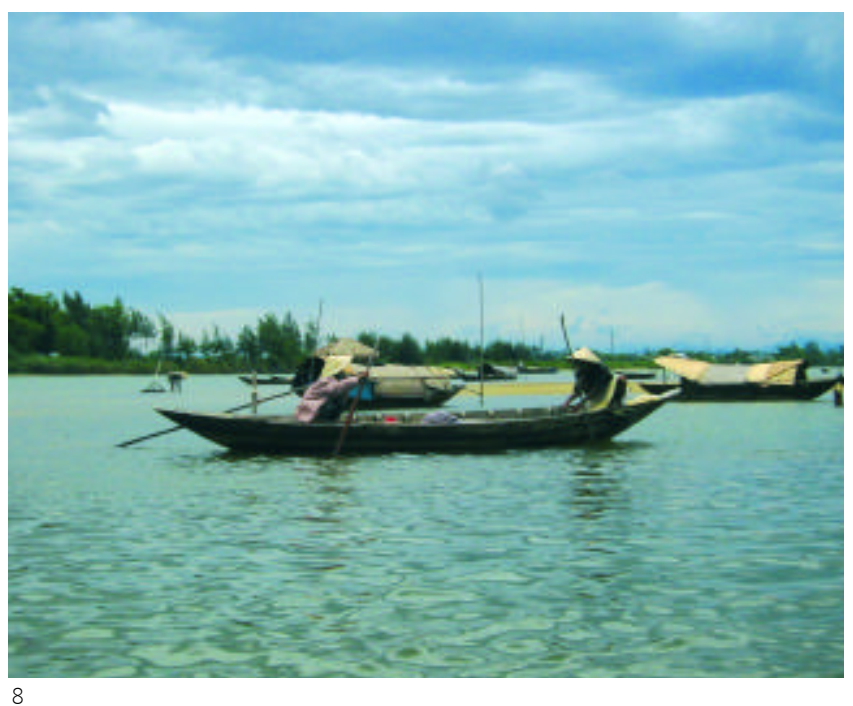

invaluables anticipaciones son situar la estética en la condición de la reproductibilidad técnica y la profunda transformación de la visión del patrimonio cultural. Preocupaciones reiteradas en el discurso postmoderno contemporáneo.

En esos textos que sin lugar a dudas inician la estética contemporánea y que W. Benjamin tituló La Obra de Arte en la época de su Reproductividad Técnica (1936) y Tesis de Filosofia de la Historia (1940), se plantean por primera vez los problemas relativos al ingreso de las nuevas tecnologías en el ámbito del arte y la cultura y las características de patrimonio cultural. Para este autor, el arte siempre ha sido susceptible de reproducción. Los griegos conocían los procedimientos de fundir y acuñar; la xilografía hizo que se reprodujese el dibujo antes de que la imprenta lo hiciese con la escritura; y también en la Edad Media se añadieron a la xilografía el grabado en cobre y el aguafuerte. Frente a todo ello, la reproducción técnica de la obra de arte contiene elementos novedosos; con la litografía, la fotografía y el cine, se transformó la naturaleza misma de la reproducción. En términos estrictos se inició la reproducción "técnica" de la obra de arte. Algunos de los rasgos típicos de esa nueva forma de reproducción son: la pérdida del carácter de existencia irrepetible; el poder poner la copia del original en situaciones inasequibles para éste; la técnica reproductiva desvincula lo reproducido del ámbito de la tradición; modifica el modo y manera de la percepción sensorial construyendo un nuevo sensorium histórico; el predominio del valor exhibitivo sobre el valor cultural.

Incluso en la reproducción técnicamente mejor acabada "falta algo" que es, en cierto sentido, el aqui y ahora de la obra de arte en su condición de existencia irrepetible. Eso que en algunas estéticas filosóficas se denominó "la autenticidad". Esa fractura del aqui y ahora que es motivada por una doble razón: en primer lugar la reproducción técnica se acredita como "más independiente" que una reproducción manual respecto del original; y en segundo 
Imágenes: Martín J. Fernández (1. Monumento del Holocausto, Berlin; 4. Muro de Berlin), Beatriz Sanjuán (2. Música en la Kartner Strabe, Viena; 7. Museo d'Orsay, París), José Manuel Santos (3. Cubos de la Memoria de Agustín Ibarrola, puerto de Llanes, Asturias), Marta Garcia de Casasola (5. Estación de autobuses en el Casar, Cáceres; 6. Museo Judío, Berlin), Isabel Luque (8. Vietnam).

lugar en la relación copia y original, aquella se puede poner en situaciones que el original no podría tener.

La reproducción técnica también modifica el modo y la manera de la percepción sensorial de las colectividades. Se crea una sensibilidad de masas (un sentido para lo igual en el mundo), ajena a períodos anteriores, que aspira a "acercar" espacial y humanamente todas las cosas, como también "adueñarse" ante todo de la imagen, la copia, la reproducción. Pero también esa reproductibilidad posibilita la experimentación "simultánea" y masiva de las obras de arte; que por ejemplo, no garantizaba la pintura en épocas anteriores.

En la recepción de la obra se modifican los acentos. Si el valor cultural caracteriza la experiencia estética en la reproducción no-técnica, en la nueva reproductibilidad el acento es en el valor exhibitivo. Del arte al servicio del culto y el ritual, los diversos métodos de su reproducción técnica han aumentado en fuerte grado las posibilidades de exhibición de la obra. Un "corrimiento" cuantitativo que conlleva una "modificación cualitativa" de su naturaleza. Para Benjamin, experimentamos una especie de preponderancia absoluta de su valor exhibitivo, aunque no desaparezca del todo el valor cultual.

Benjamin también invierte la orientación hacia el futuro que caracteriza en general a la modernidad y al arte moderno, hasta trastocarla en una orientación aún más radical hacia el pasado. La esperanza de un futuro subversivo se cumple necesariamente mediante la memoria del pasado oprimido. Existe una deuda que la actualidad tiene contraida con el pasado, una solidaridad con todos los que por la mano del hombre han sido heridos y maltratados; la cual sólo puede testimoniarse con la fuerza de la memoria de lo aún olvidado y reprimido. No debe existir solidaridad exclusivamente con el futuro, tenemos que reconstruir las huellas históricas de todo diálogo pasado suprimido.

Por tanto hay que desconfiar del tesoro de bienes culturales transmitidos entre generaciones en dos escenarios: por el criterio de dominación con que han sido seleccionados y por la asimetría de la relación entre las actividades apropiadoras con los objetos del pasado que son término de la apropiación. Tanto el criterio de selección de esos bienes culturales como los objetos que pueden ser apropiados de ese "pasado privilegiado" están cargados de barbarie y dominación. Toda época pasada contiene un horizonte de expectativas no-satisfechas que es necesario rememorar para una verdadera emancipación humana.

"Practicada esta inversión, pueden compenetrarse dos ideas: la convicción de que la continuidad del plexo que representa la tradición viene fundada tanto por la barbarie como por la cultura; y la idea de que cada generación actual no sólo es responsable del destino de las generaciones futuras, sino también del destino que sin merecerlo sufrieron generaciones pasadas" (Habermas, 1989:26).
A partir de W. Benjamín y las postmodernidades reflexivas contemporáneas se intuye que estamos experimentando diversos y complejos movimientos de reconceptualización y resemantización del patrimonio. El primer desplazamiento es el reconocimiento del patrimonio no sólo incluyendo la herencia pasada, sino también los recientes bienes y expresiones culturales, visibles e invisibles, tangibles e intangibles. El segundo movimiento es la expansión de la política patrimonial de lo producido en el pasado, a los usos sociales concretos que relacionan esos bienes con las necesidades contemporáneas de las mayorías. El tercer pliegue es el rompimiento de la selección de los bienes culturales reducidos a las clases hegemónicas, hacia la apertura al reconocimiento de bienes materiales y simbólicos de otras clases y grupos sociales. El cuarto desplazamiento, una aún brumosa transformación de la conciencia del tiempo, que no sólo se abre al futuro sino que incrementa su responsabilidad y memoria con las promesas todavía incumplidas del pasado.

Movimientos que presionan una reconceptualización acompañada de seis profundas cuestiones teóricas y políticas: a) Patrimonio cultural y desigualdad; b) Su construcción imaginaria en relación con la cultura nacional; c) Los usos del patrimonio; d) Los propósitos e imaginarios de la preservación; e) El patrimonio en la época de las industrias culturales; f) Los criterios estéticos y filosóficos para valorarlo, preservarlo y difundirlo. Todas cuestiones que afectan directamente el sentido de la diversidad y problematizan perspectivas legalistas, arcaizantes y folcloristas del patrimonio.

\section{Bibliografía}

AA. VV. (2003) Propuestas literarias en el marco de las nuevas tecnologías de la información. Bogotá: Convenio Andrés Bello, 2003

BENJAMíN, Walter (1982) Discursos interrumpidos I. Madrid: Editorial Taurus, 1982

CARRERA DÍAZ, Gema y DIETZ, Gunther (coords.)(2005) Patrimonio inmaterial y gestión de la diversidad. Instituto Andaluz de Patrimonio Histórico. Consejeria de Cultura, 2005

CONNOR, Steven (1996) Cultura Postmoderna. Madrid: Ediciones Akal, 1996

DE VICENTE, Alfonso (1989) El arte en la postmodernidad. Todo vale. Barcelona: Ediciones del Drac, 1989

HABERMAS, Jurgen (1989) El discurso filosófico de la modernidad. Madrid: Editorial Taurus, 1989

HELLER, Agnes (1997) La modernidad desde una perspectiva postmoderna en Estudios Ocasionales. Bogotá: Universidad de los Andes, 1997

LYOTARD. Jean-François (1989) La condición postmoderna. Madrid: Ediciones Cátedra, 1989

VALENZUELA, José Manuel (coord.) (2003) Los estudios culturales en México. México: Fondo de Cultura Económica, 2003 